University of Nebraska - Lincoln

DigitalCommons@University of Nebraska - Lincoln

Community and Regional Planning Program:

Faculty Scholarly and Creative Activity

Community and Regional Planning Program

2008

\title{
Linking planning theories with factors influencing local environmental-plan quality
}

Zhenghong Tang

University of Nebraska - Lincoln, ztang2@unl.edu

Follow this and additional works at: https://digitalcommons.unl.edu/arch_crp_facultyschol

Part of the Urban, Community and Regional Planning Commons

Tang, Zhenghong, "Linking planning theories with factors influencing local environmental-plan quality" (2008). Community and Regional Planning Program: Faculty Scholarly and Creative Activity. 5.

https://digitalcommons.unl.edu/arch_crp_facultyschol/5

This Article is brought to you for free and open access by the Community and Regional Planning Program at DigitalCommons@University of Nebraska - Lincoln. It has been accepted for inclusion in Community and Regional Planning Program: Faculty Scholarly and Creative Activity by an authorized administrator of DigitalCommons@University of Nebraska - Lincoln. 
The definitive, peer-reviewed and edited version of this article is published in Environment and Planning B: Planning and Design 36 (2009), pp. 522-537; doi: 10.1068/b34076 Copyright (C) 2008 Pion Ltd. Used by permission.

\title{
Linking planning theories with factors influencing local environmental-plan quality
}

\author{
Zhenghong Tang \\ Community and Regional Planning Program, 302 Architecture Hall, University of Nebraska-Lincoln, Lincoln, \\ NE 68588-0105, USA; email zhenghongtang@hotmail.com
}

\section{Samuel D. Brody}

Environmental Planning and Sustainability Research Unit, Department of Landscape Architecture and Urban Planning, Texas A\&M University, College Station, TX 77843-3137, USA; email sbrody@tamu.edu

\begin{abstract}
The major planning theories provide a theoretical foundation for environmental planning. This study extends the major planning theories and develops a robust conceptual framework to measure the key factors influencing local environmental-plan quality. A random sample of forty Californian local comprehensive land-use plans and associated planning processes is analyzed to identify the critical factors influencing environmental-plan quality. Results from multiple regression analysis indicate that regular updating, environmental-information management and sharing, and planners contribute significantly to local environmental-plan quality. The findings expand established planning theories and practice by suggesting ways to improve local environmental-plan quality.
\end{abstract}

\section{Introduction}

Many recent studies have made significant progress in understanding planning theories and plan quality. Two critical theoretical studies (Lawrence, 2000; Richardson, 2005) have highlighted the major planning theories and provided a theoretical foundation for environmental planning and management; however, few, if any, studies extend theoretical definitions to the empirical measurement of these theories in practice. An obvious gap persists between these theories and the empirical studies in addressing the factors that may influence environmental-plan quality. Many empirical studies have discussed factors influencing plan quality, such as local commitment (Norton, 2005), planning mandates (Berke and French, 1994), public participation (Brody, 2003a; Brody et al, 2003), intergovernmental collaboration (Burby and May, 1998), and plan implementation (Berke et al, 2006; Brody and Highfield, 2005; Laurian et al, 2004). These studies fall short when it comes to linking empirical results to planning theories or providing a conceptual framework that systematically identifies the critical factors associated with environmental-plan quality.

Thus, the objective of this study is to identify the major factors affecting local environmental-planning quality in California. We seek to answer the following research questions. (1) What are the components of a conceptual model that extend the major planning theories in environmental-plan quality? (2) Which factors are influencing local environmental-plan quality? (3) How can we improve local environmental-plan quality?

\section{Conceptual model: dependent and independent variables}

Our study begins by extending the major planning theories by developing a conceptual model to explain which factors can contribute to local environmental-plan quality (figure 1). This model identifies and describes the connection between five planning theories and the independent variables that may influence local environmental quality. 


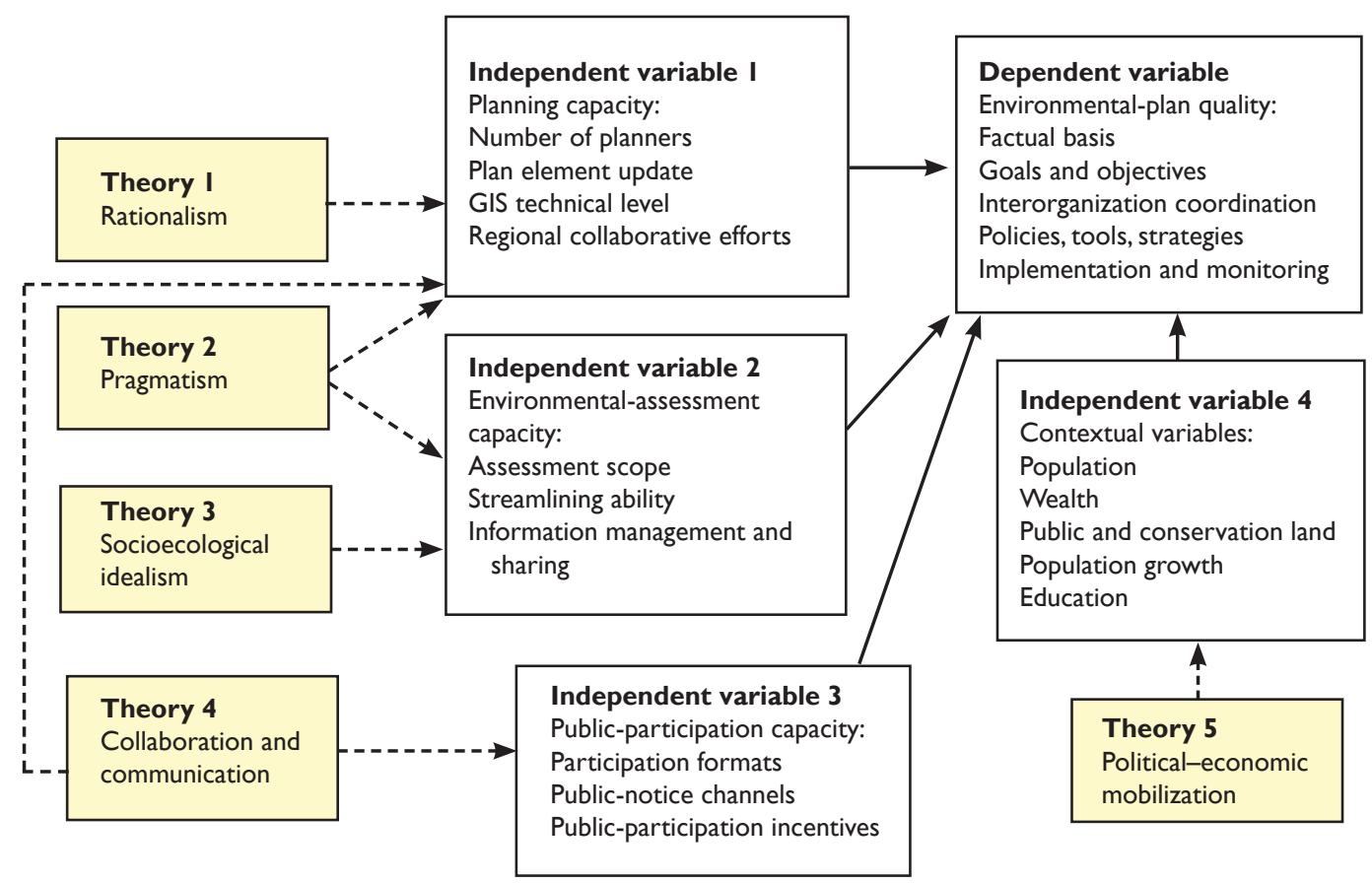

Figure I. A conceptual model for assessing environmental-plan quality.

\subsection{Dependent variable: environmental-plan quality}

The dependent variable of the conceptual model is the environmental-plan quality. This study uses local comprehensive land-use plans to evaluate environmental-plan quality, since this can provide an ideal bridge to the measurement of environmental-planning capacity at local jurisdictional levels.

Plan quality was initially conceptualized as factual basis, goals, and the policy's plan components (Baer, 1997; Berke and French, 1994; Berke et al, 1996). Brody (2003b) extended this conception of plan quality by adding two components, interjurisdictional coordination and plan implementation. Numerous recent empirical studies have focused on evaluating the plan quality of natural hazards (Brody, 2003c; Burby, 2005; Olshansky, 2001), ecosystem management (Brody, 2003a; 2003b; Brody and Highfield, 2005), sustainability (Berke, 2002; Berke and Conroy, 2000; Conroy and Berke, 2004), and urban sprawl (Brody et al, 2006). Although major achievements were made in previous studies, few studies have considered environmental impacts systematically and assessed environmental-planning quality for local comprehensive land-use plans.

On the basis of the studies listed above, this study conceptualizes an environmental plan as having five components: (1) factual basis; (2) goals and objectives; (3) inter-organization coordination; (4) policies, tools, and strategies; and (5) implementation and monitoring. The dependent variable is the environmental-plan quality that is measured by these five components. On the basis of the major literature on plan quality (Brody, 2003b; 2003c; 2003d; Brody and Highfield, 2005; Burby, 2005) and environmental assessment (Elling, 2000; Fischer, 2003; Pendall, 1998), we developed a plan-evaluation protocol, consisting of 112 indicators, to measure each component of environmental-plan quality. This study assumes that the plan-quality-evaluation protocol covers the entire plan contents rather than only the environmental section or any similar section. 


\subsection{Independent variable: factors influencing environmental-plan quality}

The major planning theories provide a theoretical foundation to develop a robust conceptual framework and identify the key factors of environmental-plan quality as four sets of variables: planning capacity, environmental-assessment capacity, public-participation capacity, and contextual characteristics.

\subsubsection{Planning capacity}

Planning capacity is rooted in the theory of rationalism, which emphasizes building an idealized model pursuing a simple, explicit, adaptable, logical, consistent, and systematic planning process (Lawrence, 2000; Richardson, 2005). The rational planning theory supports using an adequate number of qualified planners, regular updating of plans, and improving technical skills to build strong planning capacity in local environmental planning. In addition, the theory of pragmatism suggests that an efficient pragmatic planning process can eventually improve plan effectiveness (Lawrence, 2000). Local land-use planning is a complex process involving geographic, social, and economic settings, which can be affected by jurisdictional frameworks and planners' values and experiences (Forester, 1984). In this study, planning capacity is measured by the number of planners, plan updates, professional technical skills, and regional collaborative efforts.

The first measure is the number of planners. Planners are associated with increased levels of personnel, financial resources, technical expertise, and commitment to build a high-quality environmental plan (Brody, 2003a; Brody et al, 2003; Burby and May, 1998). Planning staff serve as internal consultants by developing the specialized skills needed by the planners. They handle administrative duties such as dealing with correspondence and meeting minutes, and acquiring technical resources.

The second factor in measuring planning capacity is the most-recent plan update. Plan updates are an effective way to improve environmental-plan quality. Local comprehensive landuse planning is a dynamic process that is based on a snapshot of jurisdictional values, politics, and economic and environmental conditions at a particular planning range. A local plan should reflect changes and continually monitor the relevance of land-use plan elements to ensure their consistency with evolving conditions. Planning updates can provide important insights to strengthen plan quality.

Third, professional technical skills are assessed. Technical skill has been identified as an important factor for preparing high-quality plans (Berke and French, 1994). Geographical information systems (GIS) are an ideal tool for analyzing environmental phenomena with spatial and temporal dimensions, and for analyzing spatial coincidence, adjacency, and network. GIS can help planners to understand precisely where critical environmental resources are situated and the degree to which they are in need of protection. This spatial technique helps planners make proactive choices about the strategic management of humans impacting the existing environment.

The fourth factor contributing to planning capacity is regional collaborative effort. Berke et al (1989) found that interorganizational relationships have a significant influence on the adoption of local planning measures. Since many environmental issues are not confined within jurisdictional boundaries, regional collaborative effort must be made for planning that overlaps jurisdictional territory. Regional collaboration with other jurisdictions or agencies is critical for a local jurisdiction to develop a high-quality comprehensive land-use plan because there are many cross-boundary issues. Local jurisdictions working together and with other organizations can achieve broader goals, help to solve seemingly intractable problems, and reduce the potential for disputes in local environmental management. 


\subsubsection{Environmental-assessment capacity}

Environmental-assessment capacity is supported mainly by the major theories of pragmatism and socioecological idealism. There is increasing opinion, from the theory of pragmatism, that suggests knowledge-based experience helps to achieve an effective planning outcome; thus the building of higher-quality environmental plans can be encouraged through directing more effort into streamlining, harmonization, procedural integration, assessment scoping, and information management and sharing. Moreover, the theory of socioecological idealism emphasizes the integration of social and environmental substance into comprehensive land-use planning (Lawrence, 2000; Richardson, 2005). Thus, stronger environmental-assessment capacity can help to integrate critical environmental elements into a final environmental plan in order to reach the goal of socioecological idealism. Environmental-assessment capacity can be measured by three factors: assessment scope, streamlining ability, and information management and sharing.

The first of these factors is assessment scope, which measures the different types of proposal that have been considered in an environmental-assessment process. In order to identify particular environmental issues and to assess their potential impacts, it is necessary to set the context within which the assessment is to take place by identifying critical environmental issues or problems to be addressed, the type of environmental assessment to be undertaken, and the intended objectives of the assessment for local comprehensive land-use planning. Environmental-assessment scoping highlights environmental requirements and criteria at the outset and presents an opportunity to identify the relevant stakeholders and the availability and quality of data, and to determine a set of appropriate tools and techniques to address the issues at hand. There are three major types of environmental-assessment scope. These are master-based, program-based, and projected-based environmental assessment.

The second factor in environmental-assessment capacity is streamlining ability. Streamlining refers to the process that achieves compliance with environmental laws applicable to a given proposal. The streamlining procedure allows documents developed by local comprehensive land-use planning agencies, in compliance with environmental assessment, to become a substantial part of the documentation required by other agencies. The advantages of streamlining are manifold: minimizing redundancy, reducing costs, maintaining internal consistency, and integrating functionally related goals, objectives, and policies. Streamlining procedures also help to establish a cooperative environmental-planning process, concurrent reviews, and consensus building dispute-resolution process.

The third factor, the management of sharing of environmental information, is an important part of environmental-assessment capacity. A critical element in environmental planning is the management of environmental information and sharing it with government officials, the judiciary, legal practitioners, academia, and the public at large. Web-based information is effective for the purpose of public access. This indicator is measured whether or not jurisdictions regularly provide environmental-assessment documents including a notice of preparation, environmental assessment report, negative declaration, and other information.

\subsubsection{Public-participation capacity}

Public-participation capacity is highly supported by the current dominant planning theory of collaboration and communication. This theory came from the idea of 'discursive democracy' and 'communicative rationality' (Day, 1997; Healey, 1992; Innes and Booher, 1999). Communication and collaboration can provide the opportunity to reformulate traditional rational planning through emphasizing public participation (Sinclair and Diduck, 2001), collaborative learning (Day, 1997; Godschalk et al, 2003; Innes and Booher, 1999; Lowry et al, 1997), 
and adaptive management (Healey, 1992). Environmental planning should provide a platform to debate mutually, consider rationally, and reach a consensus on public issues relevant to plan decision making, and to serve as a communicative rationality for uncertainty, inequality, conflict, and a shortage of problem-solving resources. Burby (2003) evaluated sixty plan-making processes in Florida and Washington and concluded that greater stakeholder involvement strengthens comprehensive plans. Three factors selected for analyzing public-participation capacity include participation formats, public-notice channels, and public-participation incentives.

The first factor is participation formats, which are a critical part of public participation. Public hearings and workshops are the most frequently used public-participation methods. According to the Brown Act, ${ }^{1}$ enacted in 1953, local jurisdictions in California must provide advance public notice of hearings and meetings, and these hearings and meetings must be open to the public unless exceptions apply. The public can be involved in adopting or amending a plan in a variety of ways. The major participation formats include workshops, town hall meetings, site tours, and charrettes.

The second factor is public-notice channels. Multiple public-participation channels can help to overcome linguistic, institutional, cultural, economic, and historic barriers, in order to achieve effective communication. Effective public participation should provide notice channels to enable the public to discuss the information, opinions, and concerns that may be relevant to land-use decisions. Multiple public-notice channels can thereby increase the accountability and transparency of land-use decision making and contribute to public awareness of environmental issues (Vanderhaegen and Muro, 2005). The most frequently used public-notice channels include the Internet, newspapers, radio, television, mail, notices, and community newsletters.

The third factor is public-participation incentives. Active public-participation incentive strategies should be developed, to allow for early and meaningful public participation in local comprehensive land-use planning by neighborhood organizations, development representatives, business organizations, and all other stakeholders. Public-participation incentives provide a chance for local land-use decision makers to consider seriously public concerns, and actually address those concerns. Planners should provide more incentives to foster an exchange of information and an open discussion of ideas in the public-participation process. With public-participation incentives, people have an opportunity to come together and work to solve possible environmental conflicts in a collaborative spirit that forms community solidarity. It can bring obvious benefits to all stakeholders if it occurs early in the planning cycle and is aimed at achieving consensus for the desired outcome of land-use decision making (Doelle and Sinclair, 2006). Public-participation incentives include holding evening meetings, providing daycare at public meetings, providing transportation to public meetings, holding public meetings near the project site, involving young people, posting minutes or documents on the Internet, allowing public comment by e-mail or via the Internet, and using alternative formats.

\subsubsection{Contextual characteristics}

The contextual characteristics are suggested by the theory of political-economic mobilization, which has a particular concern with social, economic, and environmental justice, stakeholder conflicts, social equality, community empowerment, and the need for structural change

1. The Ralph M Brown Act, California Government Code, sections 54950-54963 (see http://www.CFAC.org ). 
(Lawrence, 2000). The environmental-planning process can be improved through a better understanding of the insights afforded by the political-economic aspects of planning. To analyze political-economic mobilization, a possible approach is to add the contextual characteristics, such as population, economic conditions, and social background, into the factors influencing plan quality.

The contextual variables can measure the influence of background information on environmental-plan quality. On the basis of the literature on plan-quality measurement, we chose the following factors for this study: population (Berke et al, 1996), wealth (Brody et al, 2003; Scott and Willits, 1994; Van Liere and Dunlap, 1981), public land and conservation land within a jurisdiction, population growth (Norton, 2005), and education (Brody et al, 2003; Guagano and Markee, 1995).

The first factor studied is population, which has been identified by Brody (2003d) as being contextually important in local comprehensive land-use planning. Local jurisdictions with large populations may have more expertise, resources, and financial support for local land-use planning than those with small populations, but may face more environmental pressure and problems. On the one hand, a large population will increase the pressure on approval capacity within a local jurisdiction; thus, more environmental conflicts and problems are to be expected in jurisdictions with large populations. On the other hand, more environmental-planning expertise and resources may be available.

The second factor studied is wealth. Wealthy people, in comparison with poor people, often have more time and interest in environmental issues (Scott and Willits, 1994; Van Liere and Dunlap, 1981). A wealthy jurisdiction may have more money, higher awareness, and more interest in local environmental issues than a poorer jurisdiction; however, the variable of wealth (also education) may show a complex U-shaped relationship with environmental-planning efforts.

The third factor studied is public land and conservation land, both of which play a role in open spaces and the natural environment since approximately half of American land is in federal ownership. Meanwhile, due to the constraints of public-land and conservation-land ownership and geographic unsuitability, many new land-development plans are concentrated in specific areas, especially the coastal valleys, agricultural land, and ecologically sensitive foothills, which are all critical environmental components. Public land and conservation land play an important role in local natural resources, open spaces, ecosystems, biodiversity, recreation, and education. Public land and conservation land are usually subjected to high standards of environmental protections. Greater financial resources, personnel, management capacities, and collaborative efforts with multiple organizations are expected for the management of public and conservation land.

The fourth factor studied is population growth. Population-growth pressures are associated with increased levels of disturbance of environmental quality resulting in a greater perceived need to protect the environment (Norton, 2005). Rapid population growth has a substantial effect on environmental quality. Population growth may increase the consumption of natural resources and built-environment resources; at the same time, it increases waste creation and pollution. Potential land-use conflicts may increase with population growth, resulting in a greater need for environmental management.

The fifth factor studied, education, has been identified as an important factor contributing to environmental issues (Brody et al, 2003; Guagano and Markee, 1995). Communities with a highly educated population can influence the planning process and encourage higher levels of environmental protection. A community with a high education level tends to be more concerned about environmental issues than a poorly educated community. 


\section{Research methods}

\subsection{Sample selection}

The target population used in this study consists of local jurisdictions in California with comprehensive planning mandates. The sampling strategy involved the following. First, the sample of local jurisdictions was limited to those with a population of 2500 or more, in order to avoid skewing towards small communities. Second, large metropolitan areas were excluded from the sample in order to exclude their contextual factors from the sample. Thus, jurisdictions within Los Angeles, San Diego, and San Francisco were excluded from the study. Third, the sample was limited to jurisdictions with 50 miles of the coastline (including the coastal bay areas) to maintain a degree of consistency and comparability in terms of the type of environmental conditions assessed. We selected a random sample of forty local jurisdictions that satisfied our sampling strategy.

\subsection{Data collection}

Data-collection techniques involved a combination of using existing information and the gathering of primary data. Most of the local jurisdiction comprehensive plans were collected from the online service of the California Land Use Planning Information Network (see http:// www.ceres.ca.gov/planning) or the planning-agency websites of the local jurisdictions, but some plans relied on a mail request. All plans are the current versions. In some circumstances, a mail request was made to local planning officers in order to obtain the most recent changes.

For independent variables, this study used the California Planners' annual survey data from the 2003 and 2005 California Planners' Book of List (see http://www.calpin.ca.gov/Archives/Default.asp ). Missing items in these two surveys were obtained by a webpage survey or e-mails to local jurisdictions. Census data for 2000 were used to measure some contextual characteristics. Finally, GIS data were obtained from the California Spatial Information Library (http://www.gis.ca.gov/data.epl ).

\subsection{Data measurement}

The dependent variable is measured as five plan components. Within these five components, each indicator is scored on a $0-2$ scale. A score of 0 means that the indicator is not mentioned in the plan; a score of 1 means that the indicator is considered but not thoroughly; and a score of 2 means that the indicator is considered fully. On the basis of previous research (Brody, 2003c; Brody et al, 2003), total plan quality and plan component quality can be calculated using the following equations.

$$
\mathrm{PC}_{j}=\frac{10}{2 m_{j}} \sum_{i=1}^{m_{j}} I_{i}, \quad \text { and } \quad \mathrm{TPQ}=\sum_{j=1}^{5} \mathrm{PC}_{j},
$$

where $\mathrm{PC}_{j}$ is the $j$ th plan component's quality, $m_{j}$ is the number of indicators within the $j$ th plan component (scale $0-10), I_{i}$ is the score of the $i$ th indictor (scale $0-2$ ), and TPQ is the total points score for a whole plan (scale 0-50).

The first author scored all the plans. To maintain intersubjectivity, the scorer adopted pretesting and multiple testing of the plan indicators against the plan coding to reduce personal bias in score measurement and to improve personal judgment. Each plan was evaluated three times and the final score was adopted for each indicator.

This study uses the equal-weighting approach for all the indicators. The equal-weighting method avoids some personal bias in the weighting values, but this method has certain unavoidable limitations since it counts as equal all indicators that may overevaluate or underevaluate some variables.

Fifteen independent variables are measured. The number of planners are obtained from the 2005 California Planners' Book of List. The plan-update data are calculated by using the 
year 2005 minus the actual year of the conservation element. The GIS technical level is measured by the GIS data adopted in the planning process. Collaborative efforts are measured by a jurisdiction's participation in regional collaborative-planning efforts. Assessment scope is measured by the type of environmental assessment used for the last comprehensive plan update. Streamlining ability is measured by the degree of streamlining of environmental assessment. Data management and sharing is measured by the documents being regularly posted on a jurisdiction's website. Participation formats, public-notice channels, and public-participation incentives are from the 2003 survey in the California Planners' Book of List. The total population in the 2000 Census data is used to measure population. Wealth is measured by the median home value in the 2000 Census data. Population growth is measured by the percentage change in population from 1990 to 2000. Education is measured by the percentage of people over 25 years of age in 2000 with bachelor's or higher degrees. Public land and conservation land are measured by the actual percentage of public and conservation land within a jurisdiction.

\subsection{Data analysis procedures}

Our research includes two stages of data analysis. First, the study uses descriptive statistics to assess the quality of the forty local plans sampled by measuring the environmental-plan quality of the forty local jurisdictions. Second, this study uses multiple regression analysis to analyze the factors affecting the integration of a local plan and its environmental impacts. The ordinary least squares technique is used in this study to measure which factors influence local environmental-plan quality. Four types of independent variable are analyzed to identify which ones influence local environmental-plan quality.

This study conducted related statistical tests for reliability to ensure that the ordinary least squares would yield best, linear, and unbiased estimates. The results show that there is no violation of regression assumptions regarding model specification, multicollinearity, heteroskedasticity, autocorrelation, influential data or outliers, or inter-item correlation and scale reliability.

\section{Results}

\subsection{Environmental-plan quality across local jurisdictions}

Large variations among the forty jurisdictions are found in each plan component and the total plan score. The results of total plan quality show that $62.5 \%$ of local jurisdictions receive a final score below 25 points. Only three jurisdictions receive total scores above 35 points and only one jurisdiction scores above 40. Large variations for each component and total score suggest that local jurisdictions have different capacities to translate the strategic environmental assessment principles into the local comprehensive land-use planning process. The lowest scores are located in the City of Burlingame (13.32 points), the City of Milpitas (13.72 points), and Redwood City (13.92 points). Jurisdictions with low scores are expected to have the weakest planning incentives and capacities to incorporate the principle, policies, and tools of strategic environmental management into their comprehensive land-use planning process. The highest scores were achieved by the City of Berkeley (36.74 points), Orange County (38.70 points), and Santa Clara County (40.23 points). High scores suggest that these jurisdictions have stronger capacities and long-term vision to strategically direct and manage local environmental quality.

\subsection{Results for the factors influencing environmental-plan quality}

Since the number of independent variables in this study is relatively large compared with the sample size, the regression analysis groups the variables into four blocks: planning capacity, environmental assessment capacity, public participation, and contextual. The regression mod- 
Table I. Results for regression models used to analyze environmental-plan quality for forty randomly selected jurisdictions in California.

\begin{tabular}{|c|c|c|c|c|c|c|}
\hline $\begin{array}{l}\text { Regression } \\
\text { model }\end{array}$ & Variable & Coefficient & $\begin{array}{l}\text { Standard } \\
\text { coefficient }\end{array}$ & $\begin{array}{l}\text { Standard } \\
\text { error }\end{array}$ & $t$-value & $\begin{array}{r}\text { One-tailed } \\
\text { test }\end{array}$ \\
\hline \multirow{9}{*}{$\begin{array}{l}\text { Planning } \\
\text { capacity }\end{array}$} & Number of planners & 0.190 & 0.518 & 0.050 & 3.819 & 0.000 \\
\hline & Plan-update date & -0.313 & -0.366 & 0.112 & -2.803 & 0.004 \\
\hline & GIS technical level & 0.136 & 0.053 & 0.363 & 0.374 & 0.355 \\
\hline & Collaborative efforts & -0.284 & -0.069 & 0.550 & -0.516 & 0.304 \\
\hline & Constant & 25.029 & 3.992 & 6.270 & 0.000 & \\
\hline & Sample size & 40 & & & & \\
\hline & F-ratio $(4,35)$ & 6.605 & & & & \\
\hline & Significance & 0.000 & & & & \\
\hline & Adjusted $R^{2}$ & 0.365 & & & & \\
\hline \multirow{8}{*}{$\begin{array}{l}\text { Environmental- } \\
\text { assessment } \\
\text { capacity }\end{array}$} & Assessment scope & $4.17 \mid$ & 0.349 & 1.555 & 2.682 & 0.005 \\
\hline & Streamlining ability & $\mathrm{I} .090$ & 0.216 & 0.660 & 1.652 & 0.053 \\
\hline & $\begin{array}{l}\text { Information management } \\
\text { and sharing }\end{array}$ & 3.388 & 0.481 & 0.926 & 3.657 & 0.000 \\
\hline & Constant & 9.290 & & 3.518 & $2.64 I$ & 0.006 \\
\hline & Sample size & 40 & & & & \\
\hline & F-ratio $(3,36)$ & 7.899 & & & & \\
\hline & Significance & 0.000 & & & & \\
\hline & Adjusted $R^{2}$ & 0.347 & & & & \\
\hline \multirow{8}{*}{$\begin{array}{l}\text { Public- } \\
\text { participation } \\
\text { capacity }\end{array}$} & Participation formats & 0.315 & 0.051 & 1.167 & 0.270 & 0.394 \\
\hline & Public-notice channels & 0.067 & 0.015 & 0.883 & 0.076 & 0.470 \\
\hline & $\begin{array}{l}\text { Public-participation } \\
\text { incentives }\end{array}$ & 0.331 & 0.087 & 0.778 & 0.425 & 0.337 \\
\hline & Constant & 21.603 & & 3.287 & 6.572 & 0.000 \\
\hline & Sample size & 40 & & & & \\
\hline & F-ratio $(3,36)$ & 0.201 & & & & \\
\hline & Significance & 0.895 & & & & \\
\hline & Adjusted $R^{2}$ & 0.065 & & & & \\
\hline \multirow{10}{*}{$\begin{array}{l}\text { Contextual } \\
\text { characteristics }\end{array}$} & Population & 0.008 & 0.607 & 0.002 & 4.312 & 0.000 \\
\hline & Population growth & 0.004 & 0.005 & 0.102 & 0.038 & 0.485 \\
\hline & Education & 0.056 & 0.126 & 0.090 & 0.622 & 0.269 \\
\hline & Wealth & 0.003 & 0.072 & 0.007 & 0.356 & 0.362 \\
\hline & $\begin{array}{l}\text { Public land and } \\
\text { conservation land }\end{array}$ & 0.069 & 0.145 & 0.070 & 0.989 & 0.165 \\
\hline & Constant & 17.930 & & 3.586 & 5.002 & 0.000 \\
\hline & Sample size & 40 & & & & \\
\hline & F-ratio $(5,34)$ & 4.872 & & & & \\
\hline & Significance & 0.002 & & & & \\
\hline & Adjusted $R^{2}$ & 0.332 & & & & \\
\hline \multirow{10}{*}{$\begin{array}{l}\text { Fully specified } \\
\text { model }\end{array}$} & Number of planners & 0.103 & 0.281 & 0.042 & 2.456 & 0.009 \\
\hline & Plan-update date & -0.295 & -0.344 & 0.085 & -3.482 & 0.000 \\
\hline & Assessment scope & 1.066 & 0.089 & 1.493 & 0.714 & 0.240 \\
\hline & $\begin{array}{l}\text { Information management } \\
\text { and sharing }\end{array}$ & 2.294 & 0.326 & 0.719 & 3.192 & 0.015 \\
\hline & Population & 0.004 & 0.340 & 0.002 & 2.500 & 0.008 \\
\hline & Constant & 19.367 & & 2.589 & 7.481 & 0.000 \\
\hline & Sample size & 40 & & & & \\
\hline & F-ratio $(5,34)$ & 14.942 & & & & \\
\hline & Significance & 0.000 & & & & \\
\hline & Adjusted $R^{2}$ & 0.641 & & & & \\
\hline
\end{tabular}


els analyze independent variables in each category as a systematic way to build a fully specified model. The results for the regression models are listed in Table 1.

\subsubsection{Planning-capacity variables}

The results suggest that the number of planners and plan updates make statistically significant contributions to local environmental-plan quality. The number of planners has a statistically positive impact on plan quality at the 0.001 level. High numbers of planners can bring more human resources, expertise, and personnel to the local comprehensive planning process. Therefore, more planners may lead to a higher-quality local comprehensive plan, particularly as it relates to the environmental planning. By contrast, the date of the plan update has a statistically negative impact on environmental-plan quality $(p=0.008)$. Because time to plan update is calculated by using the year 2005 minus the actual year of the conservation-plan element, a shorter period of time indicates more recent plans whereas a longer period to plan update indicates older plans. This result demonstrates that more recently updated plans have a statistically higher plan quality than the out-of-date plans. On-time and regular updating helps local comprehensive plans keep apprised of new information, conditions, regulations, and techniques, and leads to higher plan quality.

Although the effect is not statistically significant, it would be expected that the GIS technical level would increase the quality of the plan while controlling for other planning-capacity variables. Although there are many available GIS data layers related to the Californian environment at state and federal level, many jurisdictions in the study did not take full advantage of the large amount of GIS data available.

Regional collaborative efforts were measured by the jurisdictions participating in regional planning efforts. Although many theories highlighted regional collaborative efforts in planning quality (Brody, 2003d; Brody et al, 2003), this study did not find statistical significance in regional collaborative efforts on plan quality. Surprisingly, regional efforts have a negative impact on environmental-plan quality. Effective collaboration may need more planning personnel and funding. Additionally, more regional collaborative efforts may suggest more environmental conflicts across jurisdictions. Thus, the possible environmental conflicts and related regional collaborative efforts may distract a planning agency's resources and procedures away from the regular comprehensive planning.

\subsubsection{Environmental-assessment-capacity variables}

Two factors, assessment scope and environmental information management and sharing, make statistically significant contributions to environmental planning quality $(p=0.011, p=0.001$, respectively). This result suggests that broader assessment scopes will result in higher environmental-plan quality. Scoping is an important step for setting the groundwork for subsequent environmental analyses in local comprehensive land-use planning. Broader assessment scopes will lead to more types of environmental assessment for updating a local jurisdiction's comprehensive plan. A broader assessment scope will consider more development proposals in the environmental-assessment processes; thus, stronger capacities of environmental planning can be expected. If a jurisdiction conducts environmental assessment for master plans, programs, projects or equivalent activities, local comprehensive plans can benefit from these assessment activities. A broader assessment scope can improve the quality of a local comprehensive plan's factual basis, policies, tools, and implementation.

Information management and sharing also has a significant effect on environmental plan quality $(p<0.010)$. Effective environmental planning depends upon information management and sharing capacity to manage the environmental-information resources and share it with 
multiple stakeholders. Local jurisdictions with strong information management and sharing can have a higher quality environment by regularly maintaining environmental documents on their webpage including notice of preparation, environmental-impact reports, negative declaration, and declaration. Stronger information management and sharing can also increase a local jurisdiction's environmental-planning capacity.

\subsubsection{Public-participation-capacity variables}

None of the variables in the public-participation-capacity category has a statistically significant effect on our environmental-planning-quality measure. In fact, the model itself is insignificant $(p=0.895)$, indicating that the public-participation capacity in this study does not result in high-quality environmental plans. Public participation is a complex issue since it is difficult to expect participation from political, economic, technical and wide-ranging interests. In this sense, public-participation processes are criticized by participants as being ineffective, costly, and time consuming, and by governments as being inefficient. This regression result shows that effective translation of public-participation effort into practical land-use plans may be an issue that is overlooked by planning agencies.

One reason why public participation variables are insignificant in our study, when they have been found to be positively significant predictors of plan quality in other analyses (see, for example, Brody, 2003d), is the way that we measured the variables. For example, by combining several participation formats into a single measure, the partial effect of each individual technique is lost. Brody et al (2003) and Godschalk et al (2003) found that the specific-citizeninput techniques rather than the number of techniques can influence plan quality. Public hearings may have a statistically negative impact on planning quality because it is hard to balance all stakeholder interests in the consensus-building process; in contrast, they found that workshops and other types of public participation have positive impacts on plan quality. Also, increased participation could dilute the strength of technical plan elements, and powerful stakeholder interests may also steer plan content away from environmental concerns. Thus, a larger variety of public-participation avenues does not necessarily mean a higher-quality public-participation process (Brody et al, 2003).

\subsubsection{Contextual characteristics variables}

Among the five contextual-characteristics variables, only population is statistically significant $(p=0.010)$. Local jurisdictions with larger populations may have relatively more expertise and resources to conduct effective environmental planning and to deal with the possible environmental conflicts in a development process. Thus, population may be an important contextual factor when predicting environmental-plan quality at the local level. The jurisdictions with large populations often have greater environmental pressures and conflicts that result in a need for stronger environmental-planning quality. Population growth, education, wealth, public land and conservation land all suggest positive relationships with environmental-plan quality even if they are not statistically significant.

\subsubsection{Fully specified model}

From the regression analysis results of the four categories of variables, this study constructs a fully specified model to examine further the factors influencing plan quality. As mentioned above, this regression blocking technique enables analysis of numerous independent variables and arrives at a full model specification even with the limitation of a small sample. The fully specified model includes the number of planners, plan-update date, assessment scope, information management and sharing, and population of each jurisdiction in the sample. In this 
model, assessment scope does not have a statistically significant impact on plan quality when controlling other variables. The number of planners and population remains a positive impact on plan quality $(p=0.011)$. Plan-update date continues to have a negative impact on plan quality $(p=0.001)$. Information management and sharing are statistically significant and contribute to increased environmental-plan quality $(p=0.003)$. This result suggest that plan-update date, and information management and sharing are the most powerful predictors of local environmental-assessment capacity. Planning capacity associated with the number of planners also remains a very powerful predictor of local environmental-plan quality. Note, in particular, that in this fully specified model a number of the selected variables (33\% of total variables) were eventually included in the final description of the factors influencing local environmental-plan quality. To test the model specification further, or to see how robust the coefficients of independent variables were to changes in the model, we conducted a sensitivity analysis to detect the extreme bounds of the variables in the final model. The result is consistent with the findings in the fully specified model.

\section{Conclusions and discussions}

From the results we can make several conclusions regarding the factors influencing environmental-plan quality in California.

First, for planning-capacity variables, both the number of planners and the year of plan update contribute significantly to environmental-plan quality. Plan updates can help local jurisdictions keep abreast of the most recent information, conditions, regulations, and techniques in order to enhance environmental-plan quality. An on-time and regular plan-update procedure helps a local comprehensive plan to stay current with new information, conditions, regulations, and techniques. Local environmental plans must often be amended or updated frequently in order to reflect long-term jurisdiction needs. Meanwhile, better qualified planners can lead to a higher-quality environmental plan, particularly as it pertains to technically driven aspects such as environmental-impact analysis. The findings further enriched the theory of rationalism (through building stronger planning staffs) and pragmatism (through providing more regular plan-updating procedures) to achieve an explicit, logical, consistent, and systematic environmental-planning process that can eventually improve the plan quality.

Second, for environmental-assessment variables, environmental-plan quality can be raised significantly through stronger information management and sharing. Providing and sharing environmental information effectively can improve the environmental-planning activities of local jurisdictions. These findings highlight the theory of pragmatism and support the notion that a knowledge-based experience (for example, information management and sharing) helps to develop an efficient, adaptable, relevant, realistic, and pragmatic local environmental plan. Effective environmental information management and sharing also helps to integrate critical environmental elements (for example, biodiversity, ecosystems, and environmental justice), which are a critical part of the theory of socioecological idealism.

Third, although many earlier studies have highlighted the positive influence on comprehensive land-use planning of public participation (Brody et al, 2003; Godschalk et al, 2003), no variable in our model was statistically significant. This lack of findings may indicate the difficulties in reflecting the impact of public-participation capacity on local comprehensive landuse plans. The jurisdictions with strong public participation may not have better local plans; however, public participation is a positive influence on plan quality. The result identified a gap between public-participation efforts and final-plan quality. Although earlier studies (Healey, 1992) have shown the importance of public participation in local land-use planning, this study 
did not find the statistical evidence to support the hypothesis that stronger public participation can result in higher plan quality. Many earlier studies (Lawrence, 2000) have highlighted that public participation may help to cope with uncertainty and conflict and facilitate effective joint participation through identifying stakeholder interests, building more transparent decision-making processes, more creative dispute solving, and greater public involvement, however, it may also result in a longer and more costly decision-making and planning process. In addition, multiple stakeholders have different levels of power and resources to affect the decision-making process, placing unequal impacts on the quality of the final comprehensive land-use plan. Thus, it is difficult to ensure absolute equity in the distribution of benefits and disadvantages resulting from comprehensive land-use plans and the planning process. More importantly, public participants generally pay close attention to their own interests because of 'not-in-my-backyard' and 'locally unwanted-land-use attitudes' (Fischer, 2003). Public interest tends to focus on more tangible development proposals in local neighborhoods rather than abstract, comprehensive, and long-term development proposals (Altshuler, 1965). Thus, while this study measures how well local plans strategically assess and manage environmental issues, plans with more localized vision may receive relatively low scores. Finally, various public-participation techniques may have opposing influences on plan quality. As mentioned above, combining several techniques into one measure may not explain appropriately the influence of public-participation capacity on plan quality because the overall effect is negated by competing subvariables. Both the planning agencies and the environmental specialists need to concentrate on how to reflect effectively the opinions of public participants in the final local comprehensive land-use plans.

Fourth, among contextual variables, plan quality is influenced significantly by population size. Those local jurisdictions with large populations may have stronger capacities to conduct environmental planning. Other factors have a positive influence but not at a statistically significant level. The findings provide a better understanding of the theory of political-economic mobilization through an analysis of the complex influence of contextual characteristics on local environmental-plan quality.

\section{Policy implications}

The results of this regression model study reveal important insights into the factors influencing local environmental-plan quality in California and provides direction for local decision makers to improve the performance of their plans.

The first policy implication for planning jurisdictions is the installation of a regular planupdate procedure. A key finding of this study is that regular plan updates are critical for environmental-plan quality. Adaptive management is one approach that allows for changes in management policies according to changing environmental conditions and scientific information. Compared with other approaches, regular plan updating is less costly, more efficient, and practical. A regular plan update can improve plan quality by generating goals and policies geared towards the specific conditions in a local community.

The second policy implication is that jurisdictions should improve environmental-information management and sharing. To enhance the capacity for information management and sharing, the following approaches are helpful. First, local jurisdictions need to maximize the use of existing environmental information. Second, they need to remove barriers for sharing environmental information so that all stake-holders can use the spatial data. Third, they need to provide common ways to access information. The Internet, one of the most important technological opportunities, should give access to information that is important to local planners. 
The third policy implication is the education of planners and decision makers to be aware of the strategic environmental impacts. This can provide a profound way for them to change their behavior and generate proactive environmental-management practices in the long term. The findings of this study have identified planners as contributing significantly to environmental-plan quality. Planners should be educated on cumulative, and large-scale environmental issues such as biodiversity, ecosystems, global warming, and environmental justice. By increasing public awareness local jurisdictions can encourage developers and individuals to adopt cost-effective and environmentally efficient practices.

\section{Limitations and future studies}

Although this study provides initial evidence on the factors influencing local environmentalplan quality in California, it has several limitations that warrant further investigation. First, the relatively small sample size may lack adequate statistical power to detect the influence of more subtle predictors, such as participation techniques or information sharing. Future analyses should examine larger samples in order to increase statistical power, reduce the possible impact of influential data points, and generate more robust statistical conclusions that can be externalized to other jurisdictions. Larger samples may also permit analysis of individual-participation techniques and distinguish their relative effects (for example public hearings versus workshops). Second, this study is limited to plan analysis for local jurisdictions in California. Future study could make use of existing environmental-plan-quality data from other states, such as Florida, Washington, and North Carolina, for multistate comparisons. Third, this study takes a broad statistical overview in its analytical approach. Future research should involve case-study analysis and personal interviews to improve understanding of the influence of political and socioeconomic contextual conditions on the quality of adopted plans.

\section{Acknowledgments}

The authors are grateful to the anonymous reviewers for Environment and Planning B: Planning and Design for comments that have improved this paper.

\section{References}

Altshuler A, 1965, "The goals of comprehensive planning" Journal of the American Institute of Planners 31 186-195

Baer W C, 1997, "General plan evaluation criteria - An approach to making better plans" Journal of the American Planning Association 63: 329-344

Berke P R, 2002, “Does sustainable development offer a new direction for planning? Challenges for the twenty-first century" Journal of Planning Literature 17: 21-36

Berke P R, Conroy M M, 2000, "Are we planning for sustainable development? An evaluation of 30 comprehensive plans" Journal of the American Planning Association 66: 21-33 Berke P R, French S $\mathrm{P}, 1994$, "The influence of state planning mandates on local-plan quality" Journal of Planning Education and Research 13: 237- 250

Berke P R, Beatley T, Wilhite S, 1989, “Influences on local adoption of planning measures for earthquake hazard mitigation" International Journal of Mass Emergency Disasters 7: 33-56

Berke P R, Roenigk D, Kaiser E, Burby R, 1996, “Enhancing plan quality: Evaluating the role of state planning mandates for natural hazard mitigation" Journal of Environmental Planning and Management 39: 79-96

Berke P, Backhurst M, Day M, Ericksen N, Laurian L, Crawford J, Dixon J, 2006, "What makes plan implementation successful? An evaluation of local plans and implementation practices in New Zealand" Environment and Planning B: Planning and Design 33: 581-600 
Brody S D, 2003a, "Measuring the effects of stakeholder participation on the quality of local plans based on the principles of collaborative ecosystem management" Journal of Planning Education and Research 22: $407-419$

Brody S D, 2003b, "Implementing the principles of ecosystem management through local comprehensive land use planning" Population and Environment 24: 511-540

Brody S D, 2003c, "Are we learning to make better plans? A longitudinal analysis of plan quality associated with natural hazards" Journal of Planning Education and Research 23: 191-201

Brody S D, 2003d, "Examining the role of resource-based industries in ecosystem approaches to management: an evaluation of comprehensive plans in Florida" Society and Natural Resources 16: 625-641

Brody S D, Highfield W E, 2005, “Does planning work? Testing the implementation of local environmental planning in Florida" Journal of the American Planning Association 71: 159-175

Brody S D, Godschalk D R, Burby R J, 2003, “Mandating citizen participation in plan making: six strategic planning choices" Journal of the American Planning Association 69: 245-264

Brody S D, Carrasco V, Highfield W E, 2006, "Measuring the adoption of local sprawl reduction planning policies in Florida" Journal of Planning Education and Research 25: 294-310

Burby R J, 2003, "Making plans that matter: citizen involvement and government action" Journal of the American Planning Association 69: 33-49

Burby R J, 2005," Have state comprehensive planning mandates reduced insured losses from natural disasters? " Natural Hazards Review 6: 67- 81

Burby R J, May P, 1998, “Intergovernmental environmental planning: addressing the commitment conundrum" Journal of Environmental Planning and Management 41: 95-110

Conroy M M, Berke P R, 2004, “What makes a good sustainable development plan? An analysis of factors that influence principles of sustainable development" Environment and Planning A 36: 1381-1396

Day D, 1997, “Citizen participation in the planning process: an essentially contested concept? “ Journal of Planning Literature 11: 421-434

Doelle M, Sinclair A J, 2006, "Time for a new approach to public participation in EA: promoting cooperation and consensus for sustainability" Environmental Impact Assessment Review 26: 185-205

Elling B, 2000, "Integration of strategic environmental assessment into regional spatial planning" Impact Assessment and Project Appraisal 18: 233-243

Fischer T B, 2003, "Strategic environmental assessment in post-modern times" Environmental Impact Assessment Review 23: 155-170

Forester J, 1984, "Bounded rationality and the politics of muddling through" Public Administration Review 44: 23-31

Godschalk D R, Brody S D, Burry R, 2003, "Public participation in natural hazard mitigation policy formation: challenges for comprehensive planning" Journal of Environmental Planning and Management 46: 733-754

Guagano G A, Markee N, 1995, "Regional differences in the sociodemographic determinants of environmental concern" Population and Environment 17: 135-149

Healey P, 1992, "A planners day: knowledge and action in communicative practice" Journal of the American Planning Association 58: 9-20

Innes J E, Booher D E, 1999, “Consensus building and complex adaptive systems: a framework for evaluating collaborative planning" Journal of the American Planning Association 65: 412-423

Laurian L, Day M, Berke P, Ericksen N, Backhurst M, Crawford J, Dixon J, 2004, “Evaluating plan implementation: a conformance-based methodology" Journal of the American Planning Association 70: $471-480$

Lawrence D P, 2000, "Planning theories and environmental impact assessment" Environmental Impact Assessment Review 20: 607-625

Lowry K, Adler P, Milner N, 1997, "Participating the public: group process politics and planning" Journal of Planning Education and Research 16: 177-187 
Norton R K, 2005, “Local commitment to state-mandated planning in coastal North Carolina" Journal of Planning Education Research 25: 149-171

Olshansky R B, 2001, “Comprehensive land use planning for seismic safety: the Los Angeles county experience 1971-1994" Journal of the American Planning Association 67: 173-185

Pendall R, 1998, "Problems and prospects in local environmental assessment: lessons from the United States" Journal of Environmental Planning and Management 41: 5-23

Richardson T, 2005, "Environmental assessment and planning theory: four short stories about power multiple rationality and ethics" Environmental Impact Assessment Review 25: 341-365

Scott D, Willits F K, 1994, "Environmental attitudes and behavior" Environmental Behavior 26: 239-261

Sinclair A J, Diduck A, 2001, "Public involvement in EA in Canada: a transformative learning perspective" Environmental Impact Assessment Review 21: 113-136

Vanderhaegen M, Muro E, 2005, "Contribution of a European spatial data infrastructure to the effectiveness of EIA and SEA studies" Environmental Impact Assessment Review 25: 123-142

Van Liere K D, Dunlap R E, 1981, “Environmental concern: does it make a difference how it's measured? " Environmental Behavior 13: 651-676 